Check for updates

Cite this: RSC Adv., 2018, 8, 17365

Received 22nd January 2018

Accepted 17th April 2018

DOI: $10.1039 / \mathrm{c} 8 \mathrm{ra00639c}$

rsc.li/rsc-advances

\section{Halogen-free guanidinium-based perovskite solar cell with enhanced stability $\dagger$}

\author{
Narayan Chandra Deb Nath, Kicheon Yoo and Jae-Joon Lee (D) *
}

Herein, we report a new halogen-free and excellent stable perovskite, $\mathrm{GAPb}(\mathrm{SCN})_{3}$, which was prepared from the symmetric guanidinium cation $\left(\mathrm{GA}^{+}\right)$with nearly zero dipole moment, and pseudohalogen $\left(\mathrm{SCN}^{-}\right)$, for the fabrication of stable perovskite solar cells. GAPb(SCN) 3 exhibits an orthorhombic crystal phase, with optical band gap of $1.43 \mathrm{eV}$. The orthorhombic crystal phase shifted to a cubic phase, due to the formation of $\mathrm{PbS}$ beyond $150{ }^{\circ} \mathrm{C}$. GAPb $(\mathrm{SCN})_{3}$ itself showed excellent stability upon being exposed to ambient conditions for 30 days, without degradation of its optical or crystallographic properties. This superior stability could be attributable to the strong electrostatic interaction between $\mathrm{SCN}^{-}$and $\mathrm{Pb}^{2+}$, and hydrogen bonding between $\mathrm{SCN}^{-}$and $\mathrm{GA}^{+}$. Even though it has a suitable band gap, it exhibited a significantly lower efficiency of ca. $0.11 \%$. The very low performance could be attributable to the significantly low light absorption coefficient, and large non-radiative recombination of photo-induced charges via an oxidized form of $\mathrm{S}$ at the $\mathrm{TiO}_{2}$ /perovskite interface.

\section{Introduction}

Perovskites $\left(\mathrm{MAPbX}_{3}, \mathrm{X}=\mathrm{Cl}, \mathrm{Br}\right.$, or I and $\left.\mathrm{MA}=\mathrm{CH}_{3} \mathrm{NH}_{3}\right)$ have distinguished themselves from other photovoltaic materials due to their unique features, which include a strong light absorption coefficient $\left(1.5 \times 10^{4} \mathrm{~cm}^{-1}\right.$ at $\left.550 \mathrm{~nm}\right)$, tunable band gap, ambipolar charge transport, long carrier lifetime, and lowcost solution-processability. ${ }^{\mathbf{1 , 2}}$ The remarkable increase in the efficiency of perovskite-based solid-state solar cells (PSCs) from $3.8 \%$ to over $21 \%$ in 5 years has attracted much attention in the solar cell community. ${ }^{3-8}$

Despite the success in their photovoltaic performance, PSCs still face several critical challenges, such as device stability under ambient conditions. ${ }^{9}$ In particular, bare MAPbX $_{3}$ itself cannot survive in atmospheric moisture, resulting in the instability of PSCs under ambient conditions. ${ }^{10}$ Therefore, PSCs have to be fabricated mostly in an inert atmosphere. Although this seriously limits the application of the devices, an effective solution to this issue still remains a major obstacle to overcome for the commercialization of PSCs. ${ }^{11-13}$

While a water-resistive coating, prepared by employing hydrophobic poly(methylmethacrylate) on HTM, has been used to improve the stability of PSCs, the intrinsic vulnerability of perovskites to moisture remains unchanged. ${ }^{13}$ A layered hybrid perovskite, formed by incorporating phenylethylammonium $\left(\mathrm{C}_{6} \mathrm{H}_{5}\left(\mathrm{CH}_{2}\right)_{2} \mathrm{NH}_{3}^{+}\right)$in $\mathrm{MAPbI}_{3}$ perovskite, has been shown to

Department of Energy \& Materials Engineering, Research Center for Photoenergy Harvesting \& Conversion Technology (phct), Dongguk University, Seoul, 100-715, Republic of Korea. E-mail: jjlee@dongguk.edu; Tel: +82-2-2260-4979

$\dagger$ Electronic supplementary information (ESI) available. See DOI: 10.1039/c8ra00639c exhibit better moisture stability. ${ }^{\mathbf{1 2}}$ In addition, mixed halide perovskites, $\mathrm{MAPbI}_{3-x} \mathrm{Br}_{x}$, formed by replacing 10-15 mol\% iodide $\left(\mathrm{I}^{-}\right)$with $\mathrm{Br}^{-}$, has also been shown to possess better moisture stability, which was attributed to the stronger interaction between $\mathrm{Br}^{-}$and $\mathrm{MA}^{+}{ }^{6}$ Similar observations have been reported for the mixed perovskite $\mathrm{MAPbI}_{3-x}(\mathrm{SCN})_{x}$, which involves the partial replacement of $\mathrm{I}^{-}$with pseudohalide (thiocyanate, $\left.\mathrm{SCN}^{-}\right) \cdot{ }^{\mathbf{1 4 - 1 6}}$ This anion has similar properties to $\mathrm{I}^{-}$, such as a similar ionic radius. The incorporation of $\mathrm{SCN}^{-}$groups into the sensitizer or redox couple of a dye-sensitized solar cell (DSSC) has been shown to be a useful strategy to enhance the cell performance. ${ }^{17,18}$ PSCs based on $\mathrm{MAPbI}_{3-x}(\mathrm{SCN})_{x}$ exhibit better intrinsic stability in humid air than conventional $\mathrm{MAPbI}_{3}$ perovskite. ${ }^{\mathbf{1 4 , 1 5 , 1 9}}$ The strong interaction between $\mathrm{SCN}^{-}$and $\mathrm{Pb}^{2+}$ contributes to improving the humid air stability of the perovskites. ${ }^{19}$

Meanwhile, some studies have examined the structure and electronic properties of $\mathrm{GAPbI}_{3}$ perovskite (where GA = $\left.\mathrm{C}\left(\mathrm{NH}_{2}\right)_{3}\right)$, which contains the larger GA cation with nearly zero dipole moment, and have suggested that the high thermodynamic stability and favorable band gap of $\mathrm{GAPbI}_{3}$ could make it a potential and stable candidate for future photovoltaic applications. ${ }^{20-22}$ Recently, the perovskite $\mathrm{MA}_{1-x} \mathrm{GA}_{x} \mathrm{PbI}_{3}$, which is based on a combination of GA/MA cations, was reported to exhibit an average PCE of over 19\%, with excellent device stability. ${ }^{23}$ The introduction of GA increased the number of interactions (e.g., hydrogen bonding) in the $\mathrm{MAPbI}_{3}$ crystal, which seemed to be the ultimate cause behind the superior stability.

In this study, we have developed a new perovskite material, $\mathrm{GAPb}(\mathrm{SCN})_{3}$, prepared from symmetric $\mathrm{GA}^{+}$and pseudohalogen 
$\left(\mathrm{SCN}^{-}\right)$instead of halide, for the fabrication of stable PSCs. Fig. 1 shows that $\mathrm{GAPb}(\mathrm{SCN})_{3}$ exhibits an orthorhombic crystal phase with the space group Pbcn. GAPb $(\mathrm{SCN})_{3}$ showed an excellent intrinsic stability against air for 30 days, without degradation of the optical and crystallographic properties. The excellent intrinsic stability was attributed to the strong electrostatic interaction between $\mathrm{SCN}^{-}$and $\mathrm{Pb}^{2+}$, and hydrogen bonding interactions between $\mathrm{SCN}^{+}$and $\mathrm{GA}^{+}$(Fig. 1), even though the cell efficiency with $\mathrm{GAPb}(\mathrm{SCN})_{3}$ was $c a .0 .11 \%$ PCE.

\section{Experimental section}

\subsection{Materials}

All reagents and solvents were purchased from Sigma-Aldrich, unless otherwise mentioned.

\subsection{Preparation of perovskite}

The perovskite was prepared by either a one- or two-step method. For the one-step method, the precursor solution (A) was prepared by mixing a $1: 1$ molar ratio of lead thiocyanate $\left(\mathrm{Pb}(\mathrm{SCN})_{2}\right)$ and guanidine thiocyanate (GASCN) in $N, N$-dimethylformamide (DMF). The perovskite films were prepared by spin-coating the precursor A on $\mathrm{SnO}_{2}: \mathrm{F}$ layers (FTO) $(15 \mathrm{~mm} \times$ $20 \mathrm{~mm}, 8 / \mathrm{sq}$, Pilkington Co. Ltd) at $2000 \mathrm{rpm}$ for $30 \mathrm{~s}$, followed by heating at different temperatures $\left(140-200{ }^{\circ} \mathrm{C}\right)$. For the twostep method, $\mathrm{Pb}(\mathrm{SCN})_{2}$ was first dissolved in dimethyl sulfoxide (DMSO) at a concentration of $500 \mathrm{mg} \mathrm{mL}^{-1}$. Then, the solution was spin coated on FTO at $2000 \mathrm{rpm}$ for $30 \mathrm{~s}$, and heated at $100{ }^{\circ} \mathrm{C}$ in air for $1 \mathrm{~h}$, to obtain a uniform film of $\mathrm{Pb}(\mathrm{SCN})_{2}$. Then, a solution of $10 \mathrm{mg} \mathrm{mL}^{-1}$ GASCN in isopropanol (IPA), was dropped on top of the $\mathrm{Pb}(\mathrm{SCN})_{2}$ film, and maintained for $30 \mathrm{~s}$, followed by spin-coating at $3000 \mathrm{rpm}$ for $25 \mathrm{~s}$. Next, the films were heated at different temperatures $\left(140\right.$ to $\left.200{ }^{\circ} \mathrm{C}\right)$. All the solutions were filtered through a $0.45 \mu \mathrm{m}$ nylon filter to obtain a clear solution.

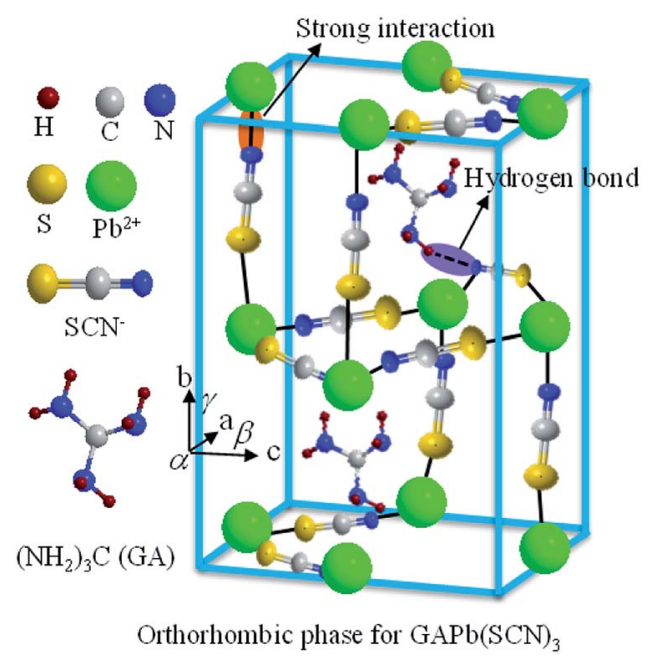

Fig. 1 Schematic of the orthorhombic crystal phase of $\mathrm{GAPb}(\mathrm{SCN})_{3}$ perovskite, along with the possible interactions inside the crystal lattice.

\subsection{Preparation of perovskite solar cells}

The preparation of $\mathrm{TiO}_{2}$ electrodes is described in the ESI. Then, the perovskite layers were prepared on the $\mathrm{TiO}_{2}$ films using an optimized one-step method only. In brief, the perovskite precursor A was dropped on $\mathrm{mp}-\mathrm{TiO}_{2}$ film, and kept for $30 \mathrm{~s}$ for better penetration, followed by spin-coating at $2000 \mathrm{rpm}$ for $30 \mathrm{~s}$. The resulting perovskite films were annealed at $150{ }^{\circ} \mathrm{C}$ in air for $30 \mathrm{~min}$. Then, spiro-MeOTAD solution, comprising $56 \mathrm{mg}$ $2,2^{\prime}, 7,7^{\prime}$-tetrakis( $N, N$-di- $p$-methoxyphenylamine)-9,9' -spirobifluorene (spiro-MeOTAD), $27 \mathrm{mg}$ of 4-tert-butyl pyridine, and $6 \mathrm{mg}$ of bis(trifluoromethane)sulfonimide lithium salt (Li-TFSI) in $1 \mathrm{~mL}$ of chlorobenzene, was spin-coated on the perovskite layer at $2500 \mathrm{rpm}$ for $20 \mathrm{~s}$, for the preparation of the HTM layer. Finally, a $160 \mathrm{~nm}$-thick Au electrode was deposited, via thermal evaporation.

\subsection{Characterization}

The UV-Vis absorption spectra of all electrodes were measured using UV-Visible spectrophotometry (Scinco, S-3100, Korea). A surface profiler (Alpha-Step IQ) was used to measure the thickness of the perovskite layer for the calculation of the molar absorption coefficient and optical band gap of the perovskite. Photoluminescence (PL) spectra were obtained using fluorescence spectrophotometry (F-4500, Hitachi) operating at $400 \mathrm{~V}$, with an excitation slit of $1 \mathrm{~nm}$, and an emission slit of $10 \mathrm{~nm}$. For the PL measurements, a thin film of GAPb $(\mathrm{SCN})_{3}$ perovskite was placed in a sample holder, and the excitation wavelength was fixed at $520 \mathrm{~nm}$ for all samples. X-ray diffraction (XRD) measurements of the samples were carried out to observe the crystalline phase using a powder diffractometer (Rigaku D/Max$2500)$ in Bragg-Bretano geometry under $\mathrm{CuK} \alpha$ radiation. The surface morphology was determined using field-emission scanning electron microscopy (FESEM, JEOL, JSM-6700F) equipped with an energy-dispersive X-ray (EDX) detector. The $J-V$ characteristics of the solar cells were measured using a photovoltaic power meter (Polaronix K101/LAB20, McScience, Korea) and a solar simulator (Polaronix K201, McScience) equipped with a $200 \mathrm{~W}$ Xenon lamp. The power of the simulated light was calibrated to $100 \mathrm{~mW} \mathrm{~cm} \mathrm{~cm}^{-2}$ (1 sun) using a standard mono-Si solar cell (PVM-396, PV Measurements Inc.), which was certified by the National Renewable Energy Laboratory (NREL). $\mathrm{X}$-ray photoelectron spectroscopy (XPS) analysis was performed using a spectrometer (PHI 5000 VersaProbe II, Japan) equipped with an $\mathrm{Al} \mathrm{K} \alpha$ monochromator X-ray source running at $20 \mathrm{kV}$, a hemispherical electron energy analyzer, and a multichannel detector. The fitting and background subtraction of XPS curves were accomplished using Casa XPS version 2.3.16 software. Ultraviolet photoemission spectroscopy (UPS) measurements were performed using a spectrometer (PHI 5000 VersaProbe II, Japan) with an ultrahigh vacuum of $3 \times 10^{-6} \mathrm{~Pa}$.

\section{Results and discussion}

The GA-cation and $\mathrm{SCN}^{-}$-based iodine-free perovskite, $\mathrm{GAPb}(\mathrm{SCN})_{3}$, was first synthesized to investigate its photoelectrochemical properties for solar cell applications. Fig. 2 

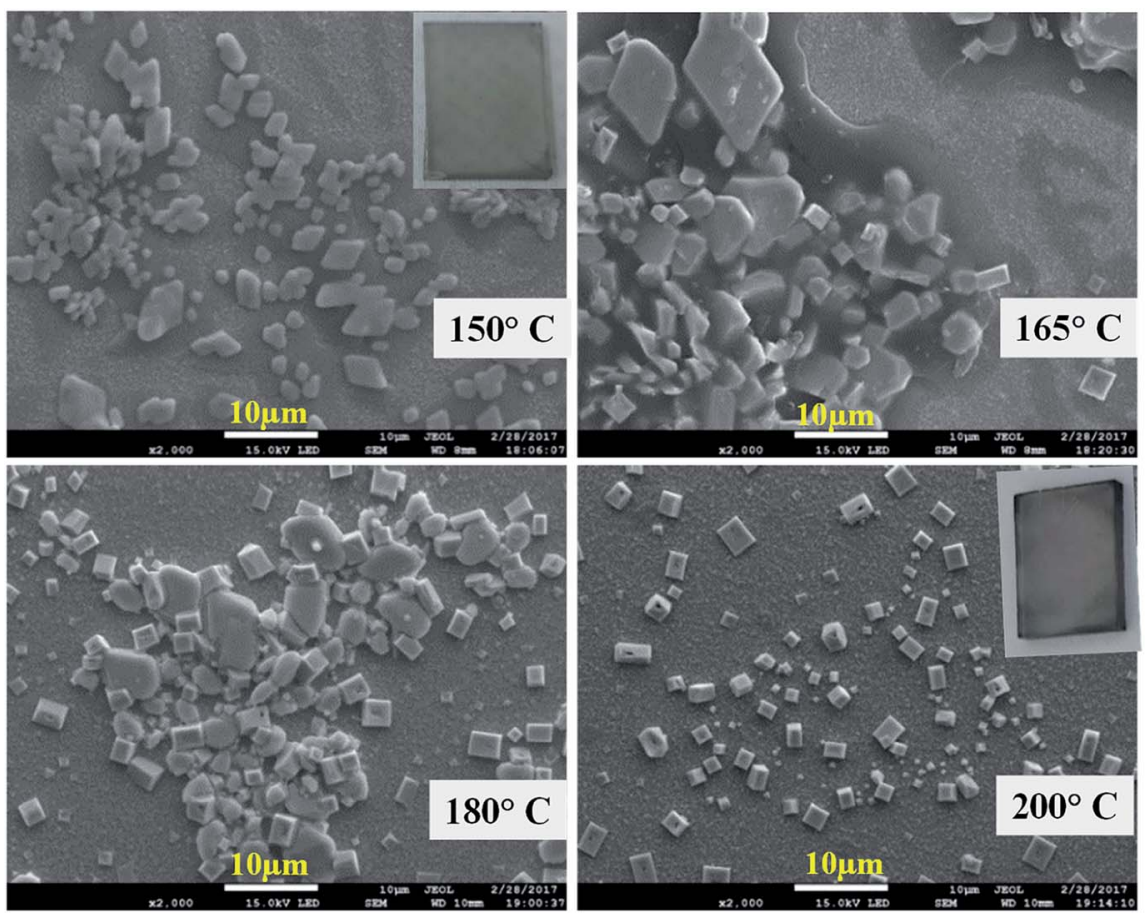

Fig. $2 \mathrm{SEM}$ images of $\mathrm{GAPb}(\mathrm{SCN})_{3}$ perovskite samples, which were prepared using a one-step method, and activated at different temperatures for 30 min (insets show the photographs of the compounds on FTO).

shows the surface morphology for different $\mathrm{GAPb}(\mathrm{SCN})_{3}$ films, prepared using a one-step method at different temperatures (150 to $200{ }^{\circ} \mathrm{C}$ ) for $30 \mathrm{~min}$. Regular-shaped morphologies started to form on FTO at $150{ }^{\circ} \mathrm{C}$. The morphology for the one-step method appeared as two-dimensional (2-D) rhombic, while for the twostep it was 3-D orthorhombic (see Fig. S1 in the ESI†). According to the crystal responses in the XRD spectra (Fig. 3 and Fig. S2 $\dagger$ ), both exhibited the orthorhombic crystal phase of $\mathrm{GAPb}(\mathrm{SCN})_{3}$ perovskite with the space group of Pnma. Lattice parameters of $a=6.78, b=5.21$, and $c=13.76(\AA)$ were obtained from the XRD spectra. These were consistent with the orthorhombic crystal phase of the $\mathrm{GA}^{+}$-based perovskite, $\mathrm{GAPbI}_{3}{ }^{21}$ They were also consistent with that for $\mathrm{MAPbI}_{3-x}(\mathrm{SCN})_{x}$, as the partial incorporation of $\mathrm{SCN}^{-}$groups resulted in a slight tilt in the crystal lattice of the conventional perovskite, $\mathrm{MAPbI}_{3}$, leading to a pseudo-orthorhombic crystal phase. ${ }^{19}$ Additional peaks, which appear at 13.1 and $27.37^{\circ}$, correspond to the hexagonal phase $(\mathrm{H}){ }^{24}$ The ratio of $\mathrm{S}$ to $\mathrm{Pb}$ was found to be $\sim 3$ (EDX spectra, Fig. S3†), supporting the formation of perovskite. The tolerance factor (TF) of $c a .1 .04$ for $\mathrm{GAPb}(\mathrm{SCN})_{3}$, calculated according to Goldschmidt's equation, $\mathrm{TF}=\left(r_{\mathrm{A}}+r_{0}\right) / \sqrt{ } 2\left(r_{\mathrm{B}}+r_{0}\right)$, where, $r_{\mathrm{A}}$ is the radius of organic cation $\left(\mathrm{GA}^{+}=3 \AA\right), r_{\mathrm{B}}$ the radius of metal cation $\left(\mathrm{Pb}^{2+}=1.33 \AA\right)$, and $r_{0}$ the radius of anion $\left(\mathrm{SCN}^{-}=2.20 \AA\right),{ }^{25}$ also suggests the formation of a perovskite material. ${ }^{26}$ Further, the N1s XPS analysis confirmed the formation of $\mathrm{GAPb}(\mathrm{SCN})_{3}$, as described in Fig. $4 \mathrm{a}^{23}$

The films activated at $140{ }^{\circ} \mathrm{C}$ showed irregular-shaped morphologies (Fig. S4a and $\mathrm{b}_{\dagger}$ ). Essentially, the films contained the starting material, $\mathrm{Pb}(\mathrm{SCN})_{2}$, which was confirmed by the XRD spectra (Fig. S4c $\dagger$ ). An additional cubic crystal (Fig. 2 and Fig. S1 $\dagger$ ) started to form at above $150^{\circ} \mathrm{C}$. The XRD spectrum of the sample activated at $165{ }^{\circ} \mathrm{C}$ highlights a deviation from the orthorhombic phase (Fig. 3 and Fig. S2†). Interestingly, all the crystals became cubic at $200{ }^{\circ} \mathrm{C}$. For the samples activated at $200{ }^{\circ} \mathrm{C}$, the XRD spectra (Fig. 3 and Fig. S2 $\dagger$ ) exhibit a totally different crystallinity. Peaks are present at 25.7, 30.2, 43, 50.9, 53.2 and $52.5^{\circ}$, corresponding to the cubic crystal phase of $\mathrm{PbS}^{27,28}$ Further, the formation of PbS is supported by the EDX spectra as having the $\mathrm{S} / \mathrm{Pb}$ (elemental) ratio of $\sim 1$ (Fig. S3†). This is attributed to the degradation of $\mathrm{SCN}^{-}$to sulfur (S) and $\mathrm{CN}^{-}$at above $150{ }^{\circ} \mathrm{C}$, which is similar to the formation of a small amount of $\mathrm{S}$ impurities observed during the preparation of $\mathrm{MAPbI}_{3-x}(\mathrm{SCN})_{x} \cdot{ }^{14,19}$ Then, $\mathrm{S}$ reacted with $\mathrm{Pb}^{2+}$ at high temperature to form PbS with a cubic crystal phase. The whole phenomenon was further confirmed by the synthesis of pure and powder forms of $\mathrm{PbS}$ from perovskite precursor A at $200{ }^{\circ} \mathrm{C}$ using an anti-solvent technique. The precursor $\mathrm{A}$ was added into octanol (as the anti-solvent), and the mixture with the ratio of $55: 45$ (octanol/precursor A) was heated at $200{ }^{\circ} \mathrm{C}$, followed by constant stirring for $30 \mathrm{~min}$. This technique nucleated large pure cubic crystals of PbS, which were characterized by SEM, XRD, and EDX (Fig. S5 $\dagger$ ). The XRD spectrum was consistent with that for $\mathrm{PbS}$ reported elsewhere. ${ }^{27}$

Further, a Lewis acid-base adduct approach was used to prepare a compact and homogeneous $\mathrm{GAPb}(\mathrm{SCN})_{3}$ film (see $\mathrm{ESI} \dagger$ for preparation), which has been previously used to prepare high-quality $\mathrm{MAPbI}_{3}$ perovskite films using DMSO as a Lewis base. ${ }^{29}$ Recently, TU was used as Lewis base for the preparation of better quality $\mathrm{FAPbI}_{3}$ films, as S-donors (TU) are stronger than O-donors (DMSO). ${ }^{30}$ In the present study, TBP and TU were used as Lewis bases. The formation of PbS cubic crystals was favored even at $150{ }^{\circ} \mathrm{C}$ for $\mathrm{TU}$, as it acted as sulfur 


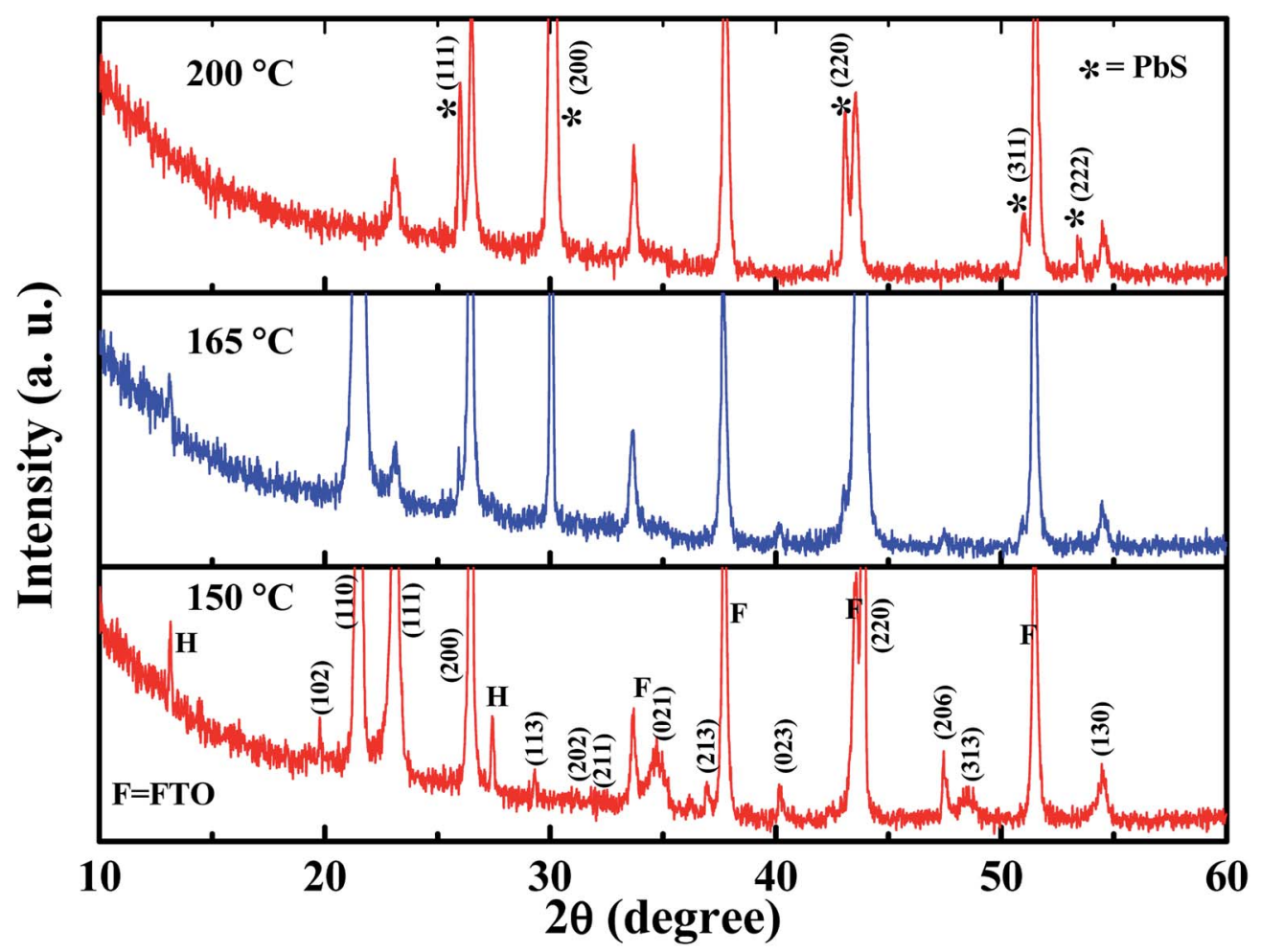

Fig. 3 XRD spectra of $\mathrm{GAPb}(\mathrm{SCN})_{3}$ perovskites prepared using the one-step method, and activated from 150 to $200{ }^{\circ} \mathrm{C}$ for 30 min.

source (Fig. S6†). However, TBP exhibited a two-dimensional (2D) rhombic structure, which also had the similar orthorhombic crystal phase of $\mathrm{GAPb}(\mathrm{SCN})_{3}$ perovskite (Fig. S7 $\dagger$ ). However, it contained few cubic crystals, even at $150{ }^{\circ} \mathrm{C}$.

Fig. 5a shows the light absorption spectrum of $\mathrm{GAPb}(\mathrm{SCN})_{3}$, prepared using the one-step method. It exhibits an absorption maximum at about $550 \mathrm{~nm}$, with the onset absorption edge of ca. $800 \mathrm{~nm}$. On the other hand, $\mathrm{GAPb}(\mathrm{SCN})_{3}$ prepared using the two-step method showed a significant low absorption in the wavelength region between 400 and $700 \mathrm{~nm}$, indicating that it is a worse absorber for solar cell applications (Fig. S8 $\dagger$ ). Hereafter, we characterized only the $\mathrm{GAPb}(\mathrm{SCN})_{3}$ perovskite prepared using the one-step method for further applications. The direct optical band gap was determined by plotting the square of the Kubelka-Munk function $(\alpha \times$ photon energy $(h v)) v s . h \nu$
(Fig. 5b), where $\alpha$ is the absorption coefficient (determined by the equation $\alpha=2.303 \times A$ (absorbance)/ $d$ (film thickness in $\mathrm{nm})$ ), $h$ is the plank constant, and $\nu$ is the photon frequency. ${ }^{31}$ This direct optical band gap was found to be about $c a .1 .43 \mathrm{eV}$, which is in accordance with previously reported theoretical values for $\mathrm{GAPbI}_{3}{ }^{21}$ This indicates that the replacement of $\mathrm{I}^{-}$ with $\mathrm{SCN}^{-}$did not affect the optical band gap much. It has also been reported that the partial replacement of $\mathrm{I}^{-}$with $\mathrm{SCN}^{-}$in the perovskite $\mathrm{MAPb}(\mathrm{SCN})_{2} \mathrm{I}$ did not affect its optical band gap. ${ }^{14}$ Then, the valence band (VB) energy of $\mathrm{GAPb}(\mathrm{SCN})_{3}$ was estimated to be $c a$. $-5.61 \mathrm{eV}$ at the vacuum level (Fig. $5 \mathrm{c}$ ), which is slightly lower than that for the conventional perovskite, $\mathrm{MAPbI}_{3}$, reported elsewhere. ${ }^{32}$ From the observed optical band gap, a conduction band (CB) energy of $c a$. $-4.17 \mathrm{eV}$ was estimated, which is slightly higher than that of $\mathrm{TiO}_{2}$. However, its
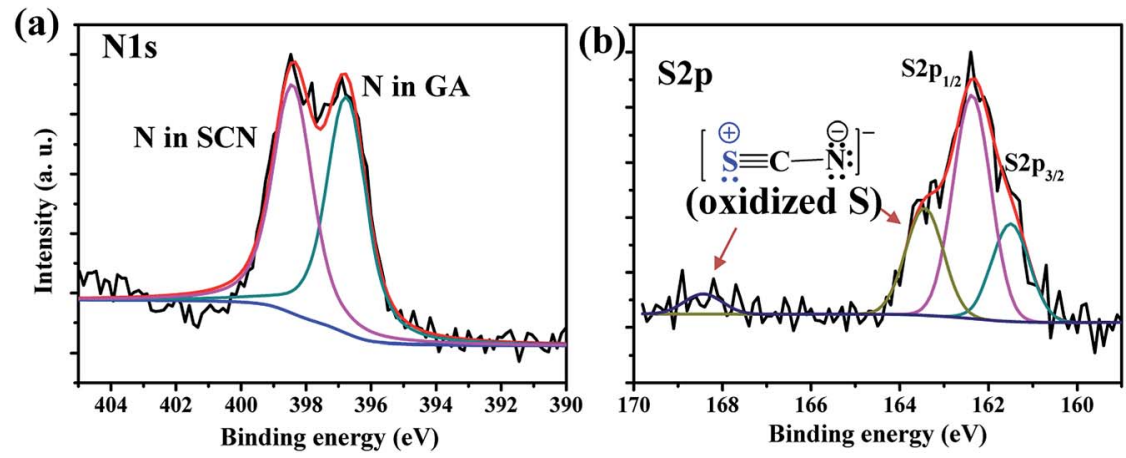

Fig. 4 (a) N1s and (b) S2p XPS spectra of $\mathrm{GAPb}(\mathrm{SCN})_{3}$ perovskite films, which were prepared by the one-step method, and activated at $150{ }^{\circ} \mathrm{C}$ for 30 min. 

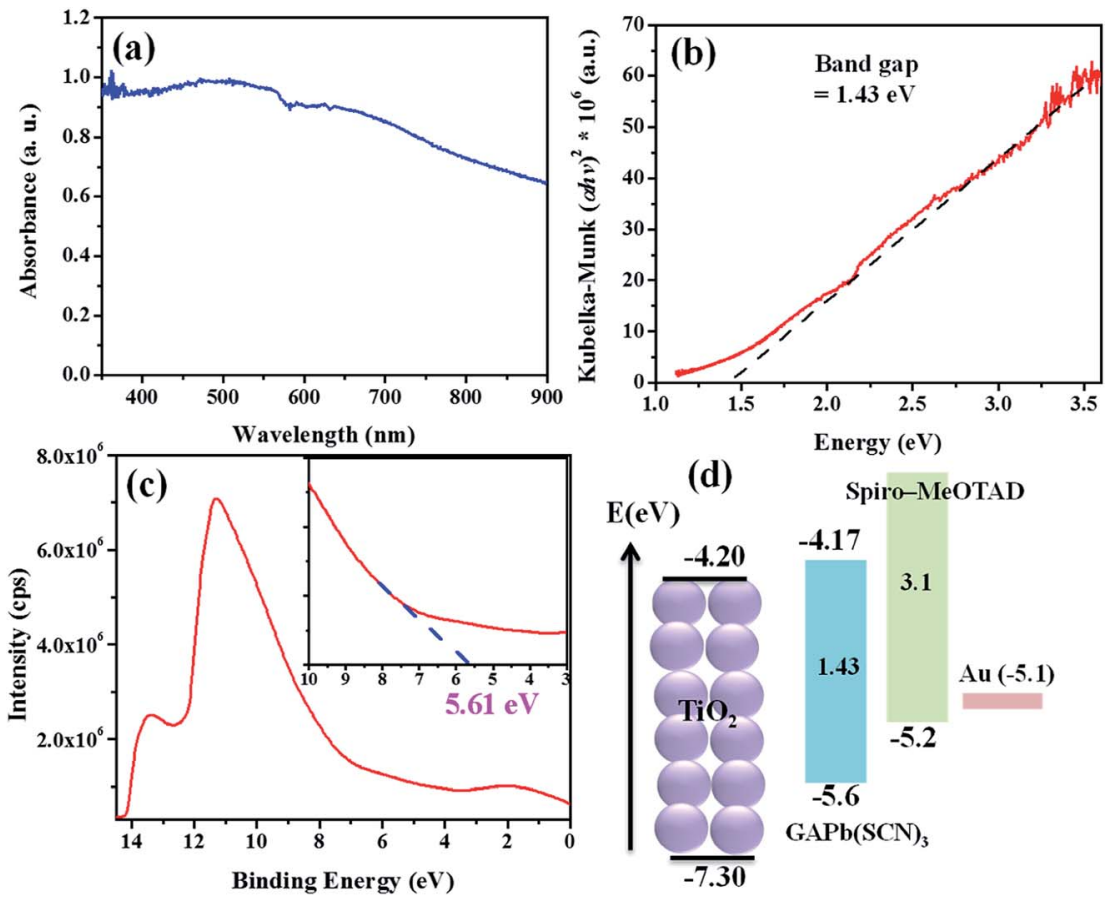

Fig. 5 (a) UV-Vis spectra, (b) Kubelka-Munk plot, (c) UPS, and (d) energy levels for GAPb(SCN) 3 perovskites prepared using the one-step method, and activated at $150{ }^{\circ} \mathrm{C}$ for $30 \mathrm{~min}$.

band positions were well aligned for charge separation alone with n-type $\mathrm{TiO}_{2}$ and p-type HTM of spiro-MeOTAD (Fig. 5d).

As mentioned above, the stability of perovskite under ambient conditions is a very concerning issue that limits its outdoor application. We therefore studied the stability of $\mathrm{GAPb}(\mathrm{SCN})_{3}$ upon exposure to air for 30 days. Fig. 6 shows the photographs, UV-Vis spectra, and XRD spectra of GAPb(SCN $)_{3}$ upon exposure to air for 30 days. The photographs clearly indicate that the color of the perovskite itself did not degrade (Fig. 6a). The identical light absorption pattern in the UVVisible spectrum suggests that the perovskite retained all of its optical properties, e.g. absorption co-efficient and optical band gap (Fig. 6b). ${ }^{14}$ The identical XRD spectrum confirms the high stability of the orthorhombic crystals of $\mathrm{GAPb}(\mathrm{SCN})_{3}$ perovskite after exposure in air for 30 days (Fig. 6c). Therefore, it is obvious that the stability of $\mathrm{GAPb}(\mathrm{SCN})_{3}$ itself is superior to that of the conventional perovskite, $\mathrm{MAPbI}_{3}{ }^{14}{ }^{14}$ This is consistent with the recent report on the perovskite $\mathrm{MA}_{1-x^{-}}$ $\mathrm{GA}_{x} \mathrm{PbI}_{3}$, which possesses a combination of GA and MA cations, in which the incorporation of GA increases the number of interactions (e.g., hydrogen bonding) in the $\mathrm{MAPbI}_{3}$ crystal, inducing superior stability. ${ }^{23}$ The excellent stability can be attributed to the strong electrostatic interaction between $\mathrm{SCN}^{-}$and $\mathrm{Pb}^{2+}$, and hydrogen bonding between $\mathrm{SCN}^{-}$ and $\mathrm{GA}^{+}$, described in Fig. 1. This is also consistent with the strong interaction existing in $\mathrm{MAPbI}_{3-x}(\mathrm{SCN})_{x}$ perovskite. $^{19}$

Then, we constructed a solar device with the $\operatorname{GAPb}(\mathrm{SCN})_{3}$ perovskite using spiro-MeOTAD as the HTM layer, and Au as counter electrode, as shown in Fig. 7a. The current-voltage $(J-V)$ curve (Fig. 7b) was measured under simulated sunlight (AM 1.5,

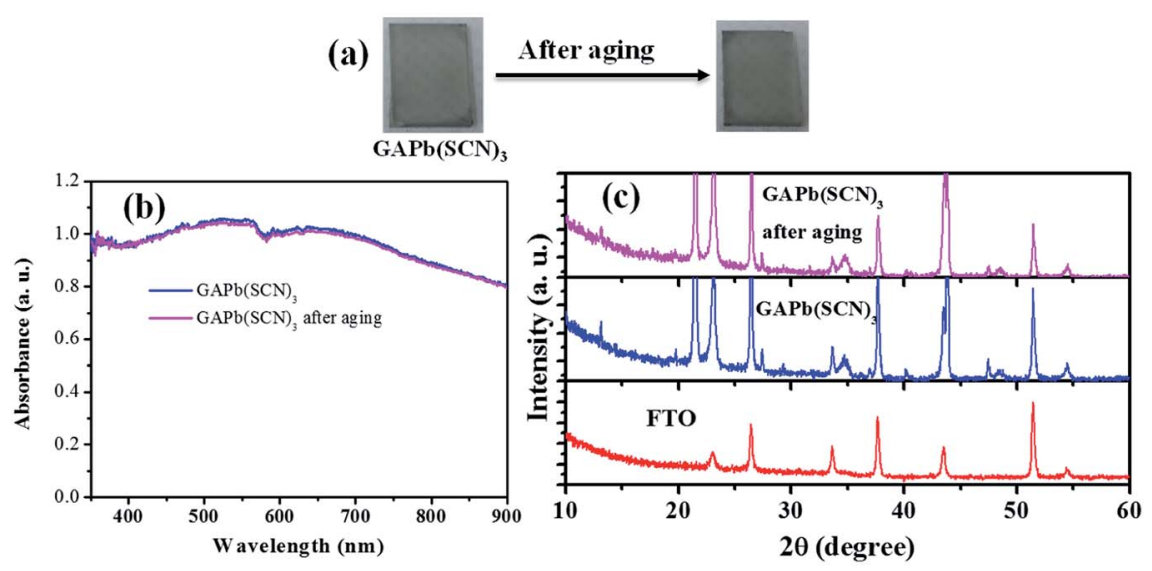

Fig. 6 (a) Photographs, (b) UV-Vis spectra, and (c) XRD spectra of $\mathrm{GAPb}(\mathrm{SCN})_{3}$ perovskite, along with aging in air for 30 days. 

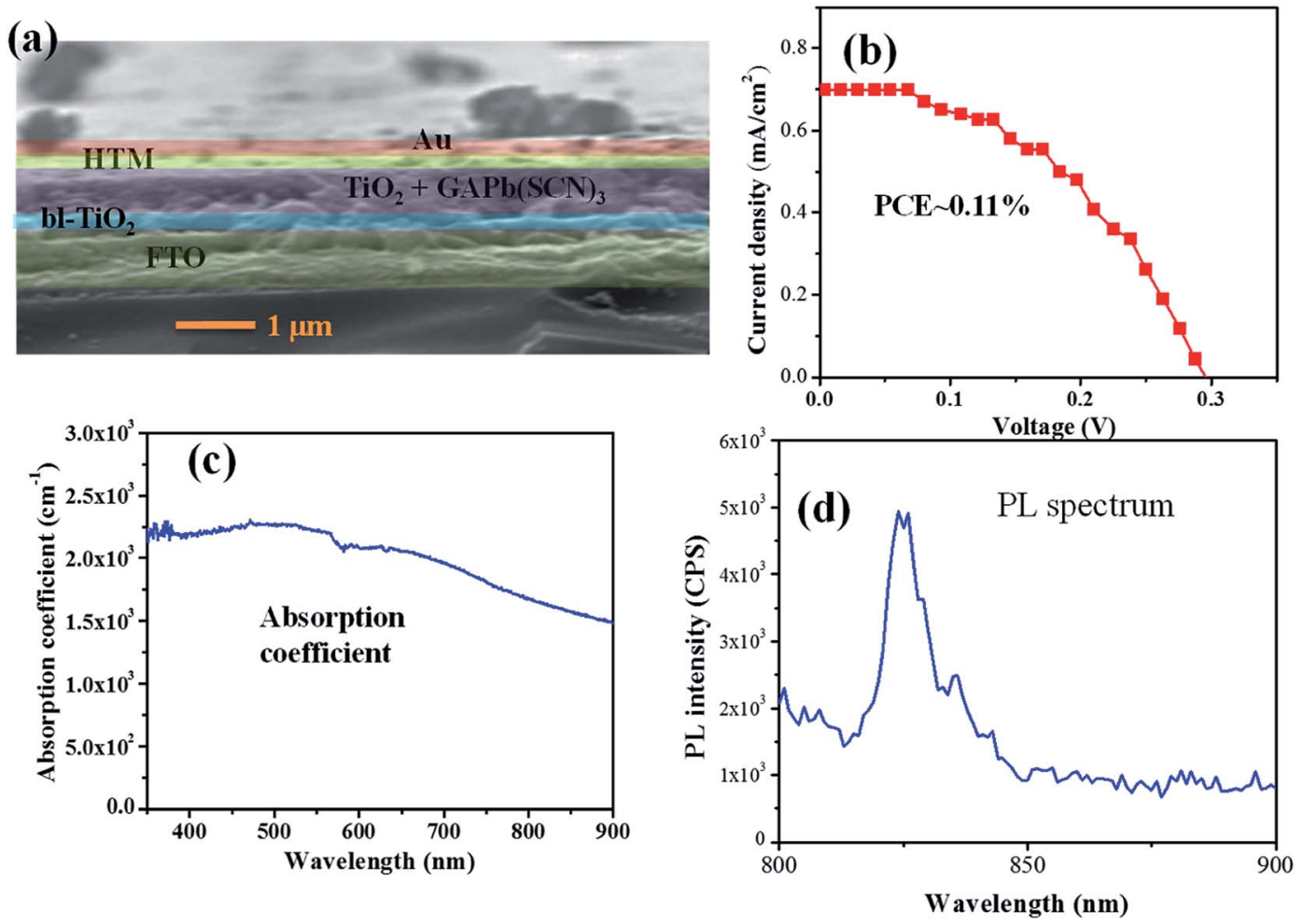

Fig. 7 (a) Device cross-sectional SEM image, (b) device current-voltage characteristic, (c) UV-Vis absorption coefficient variation, and (d) photoluminescence $(\mathrm{PL})$ spectrum (excitation wavelength $=520 \mathrm{~nm}$ ) of $\mathrm{GAPb}(\mathrm{SCN})_{3}$ perovskite films, prepared using the one-step method, and activated at $150{ }^{\circ} \mathrm{C}$ for $30 \mathrm{~min}$.

$100 \mathrm{~mW} \mathrm{~cm}{ }^{-2}$ ) illumination. The device showed a PCE of $0.11 \%$, with $J_{\mathrm{sc}}=0.70 \mathrm{~mA} \mathrm{~cm}{ }^{-2}, V_{\mathrm{oc}}=0.30 \mathrm{~V}$, and $\mathrm{FF}=55.78 \%$ (Table 1). Despite the optimized band gap of about $1.43 \mathrm{eV}, \mathrm{GAPb}(\mathrm{SCN})_{3}$ exhibited a significantly low PCE. The low PCE may be attributed to the low light absorption coefficient (Fig. 7c) and very low photoluminescence (PL) response (Fig. 7d).$^{33}$ Its low light absorption coefficient of $c a .2 \times 10^{3} \mathrm{~cm}^{-1}$ is much lower than that of the conventional perovskite, $\mathrm{MAPbI}_{3}\left(1 \times 10^{5} \mathrm{~cm}^{-1}\right),{ }^{34}$ which limits the light harvesting efficiency of the solar device. The weak PL resulted in higher non-radiative recombination at the $\mathrm{TiO}_{2} /$ perovskite interface, via the states with energies within the band gap, and surface recombination at the electron-hole selective contacts. ${ }^{33}$ The non-radiative recombination of photo-induced charges took place through the partial reduction of the oxidized form of $\mathrm{S}$ on the conjugated intermediate (3) of $\mathrm{SCN}^{-}$, described as follows:

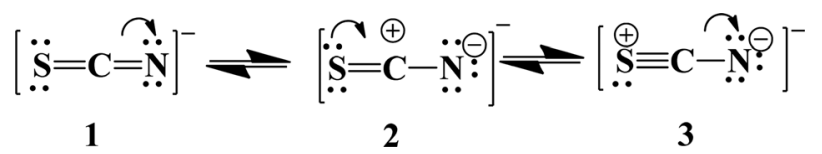

Among the three suggested intermediates, the formation of 3 was favored, because $\mathrm{N}$ is more electronegative than $\mathrm{S}$. The XPS spectrum of S2p showed extra peaks, appearing at higher energies of about $\sim 163.44$ and $168.43 \mathrm{eV}$ (Fig. 4b). These peaks could be attributable to the formation of the oxidized form of $\mathrm{S}$ in the intermediate 3 , which is consistent with the XPS results of oxidized S reported elsewhere. ${ }^{35}$ The formation of trap states, formed within the band gap of $\mathrm{GAPb}(\mathrm{SCN})_{3}$, facilitated the recombination of photo-induced charges, as well as significantly decreasing the $V_{\text {oc }}$ of the solar device. ${ }^{36,37}$ The recombination behavior was consistent with the high trap density formed by $\mathrm{Cu}^{2+}$ reduction for $\mathrm{Cu}$-based perovskite, which corresponds to a very low PCE. ${ }^{38}$

We also prepared hybrid perovskites, $\operatorname{GAPb}(\mathrm{SCN})_{3-y} \mathrm{I}_{y}(y=$ doping level of iodide $\left(\mathrm{I}^{-}\right)$ranging from 0.4 to 1.2$)$, by replacing the $\mathrm{SCN}^{-}$with $\mathrm{I}^{-}$, to reduce the recombination of photoinduced charges associated with $\mathrm{SCN}^{-}$. Rod-like shapes were obviously formed at the doping level of $y=0.4$ (Fig. 8a). In addition to the rod-shaped structures, the nucleation of round crystals was observed at $y=0.8$, which almost disappeared at the doping level of 1.2. The hybrid perovskites showed an additional absorption edge near $470 \mathrm{~nm}$, compared with that for pure $\mathrm{GAPb}(\mathrm{SCN})_{3}$ (Fig. $8 \mathrm{~b}$ ). The hybrid perovskite

Table 1 Current-voltage $(J-V)$ characteristic parameters for pure $\mathrm{GAPb}(\mathrm{SCN})_{3}$ and hybrid $\mathrm{GA}_{y} \mathrm{~Pb}(\mathrm{SCN})_{3-y} l_{y}$ perovskites $(y=$ doping level), which were prepared using the one-step method and activated at $150{ }^{\circ} \mathrm{C}$ for $30 \mathrm{~min}$

\begin{tabular}{lllll}
\hline Perovskite & $V_{\text {oc }}(\mathrm{V})$ & $J_{\text {sc }}\left(\mathrm{mA} \mathrm{cm}^{-2}\right)$ & FF $(\%)$ & PCE $(\%)$ \\
\hline $\mathrm{GAPb}(\mathrm{SCN})_{3}$ & 0.30 & 0.70 & 55.78 & 0.11 \\
$\mathrm{GAPb}(\mathrm{SCN})_{2.6} \mathrm{I}_{0.4}$ & 0.46 & 1.23 & 57.71 & 0.33 \\
$\mathrm{GAPb}(\mathrm{SCN})_{2.2} \mathrm{I}_{0.8}$ & 0.69 & 1.79 & 53.89 & 0.67 \\
$\mathrm{GAPb}(\mathrm{SCN})_{1.8} \mathrm{I}_{1.2}$ & 0.66 & 3.68 & 51.18 & 1.25
\end{tabular}



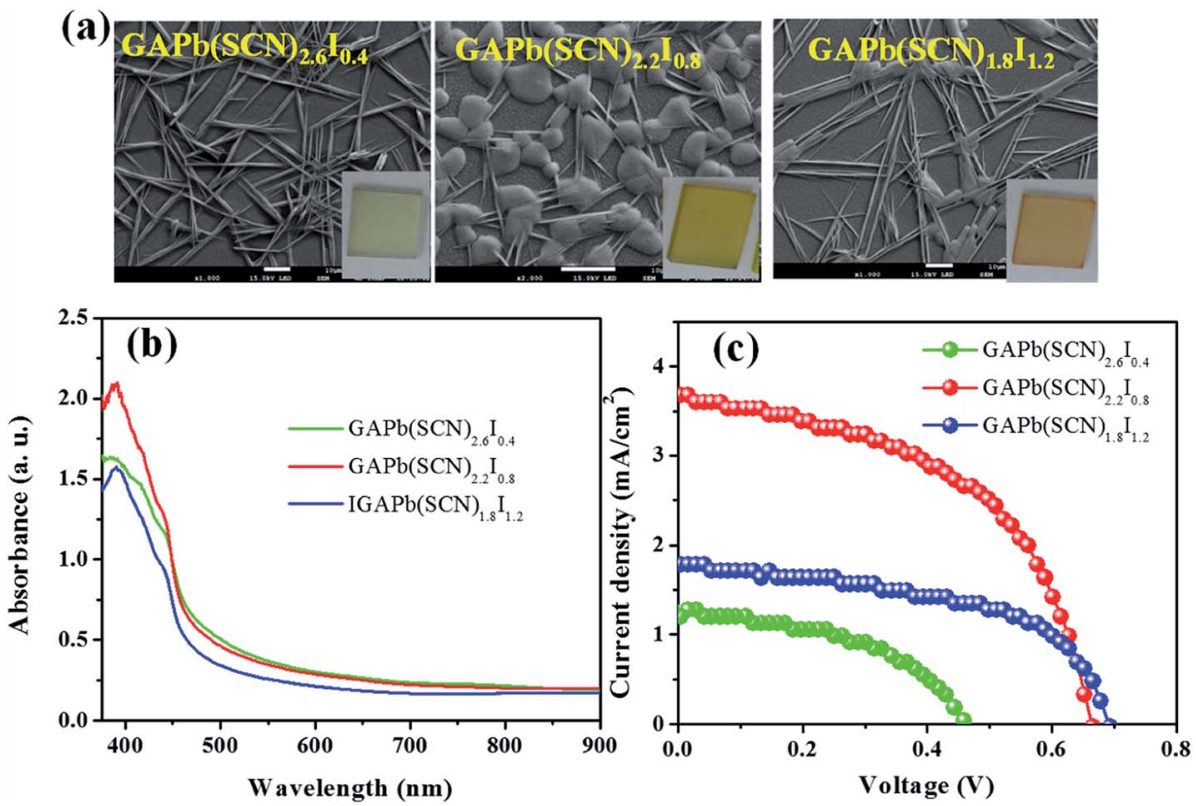

Fig. 8 (a) SEM images with photographs, (b) UV-Vis spectra, and (c) current-voltage (J-V) characteristic parameters for hybrid GA $\mathrm{Pb}_{\mathbf{y}}(\mathrm{SCN})_{3-y} \mathrm{l}_{y}$ perovskites ( $y=$ doping level), which were prepared using the one-step method, and activated at $150{ }^{\circ} \mathrm{C}$ for $30 \mathrm{~min}$.

$\left(\mathrm{GAPb}(\mathrm{SCN})_{2.2} \mathrm{I}_{0.8}\right)$ exhibited a highest PCE of $1.25 \%$ (Fig. $8 \mathrm{c}$ and Table 1), which might be associated with higher light absorption and reduced trap states due to the oxidized form of $\mathrm{S}$, compared with those for pure $\mathrm{GAPb}(\mathrm{SCN})_{3}$.

\section{Conclusions}

In this report, we prepared a new halogen-free and excellent stable perovskite, $\mathrm{GAPb}(\mathrm{SCN})_{3}$ from symmetric $\mathrm{GA}^{+}$and pseudohalogen $\left(\mathrm{SCN}^{-}\right)$for stable PSCs, which exhibited an orthorhombic crystal phase with a moderate optical band gap of $1.43 \mathrm{eV}$. The pure $\mathrm{GAPb}(\mathrm{SCN})_{3}$ perovskite could be formed at around $150{ }^{\circ} \mathrm{C}$, while a cubic $\mathrm{PbS}$ was formed beyond $150{ }^{\circ} \mathrm{C}$. At temperatures above $150{ }^{\circ} \mathrm{C}$, the $\mathrm{SCN}^{-}$ion degraded to $\mathrm{S}$, which eventually reacted with $\mathrm{Pb}^{2+}$ to form $\mathrm{PbS}$. The $\mathrm{GAPb}(\mathrm{SCN})_{3}$ perovskite showed excellent intrinsically stability upon exposure to ambient conditions for 30 days, without degradation to its optical or crystallographic properties. The orthorhombic crystal phase of $\mathrm{GAPb}(\mathrm{SCN})_{3}$ was found to be thermodynamically stable, with a strong electrostatic interaction between $\mathrm{SCN}^{-}$and $\mathrm{Pb}^{2+}$, and hydrogen bonding between $\mathrm{SCN}^{+}$and $\mathrm{GA}^{+}$. Even though it showed a suitable band gap, the device containing $\mathrm{GAPb}(\mathrm{SCN})_{3}$ exhibited a low PCE of $c a .0 .11 \%$, due to the significantly low light absorption coefficient of the perovskite, and high non-radiative recombination of photo-induced charges, caused by the formation of large trap states at the $\mathrm{TiO}_{2} /$ perovskite interface. However, a PCE of up to $1.25 \%$ was achieved by reducing the non-radiative recombination at the interface with the partial replacement of $\mathrm{SCN}^{-}$with $\mathrm{I}^{-}$in the perovskite. The PCE could be further improved by increasing the light absorption in the visible region via the partial introduction of additional cations, e.g., FA or MA in the GAPb(SCN $)_{3}$ perovskite, which is currently underway in our laboratory.

\section{Conflicts of interest}

There are no conflicts to declare.

\section{Acknowledgements}

This research was supported by Basic Science Research Program through the National Research Foundation of Korea (NRF) funded by the Ministry of Education (NRF-2015M1A2A2054996, NRF-2016R1A2B2012061). It was also supported by the Technology Development Program to Solve Climate Changes of the National Research Foundation (NRF) funded by the Ministry of Science, ICT \& Future Planning (NRF-2016M1A2A2940912). This work was also supported by the Dongguk University Research Fund of 2016.

\section{References}

1 M. A. Green, A. Ho-Baillie and H. J. Snaith, Nat. Photonics, 2014, 8, 506-514.

2 H. S. Jung and N.-G. Park, Small, 2015, 11, 10-25.

3 A. Kojima, K. Teshima, Y. Shirai and T. Miyasaka, J. Am. Chem. Soc., 2009, 131, 6050-6051.

4 H.-S. Kim, C.-R. Lee, J.-H. Im, K.-B. Lee, T. Moehl, A. Marchioro, S.-J. Moon, R. Humphry-Baker, J.-H. Yum, J. E. Moser, M. Grätzel and N.-G. Park, Sci. Rep., 2012, 2, 591.

5 J. Burschka, N. Pellet, S.-J. Moon, R. Humphry-Baker, P. Gao, M. K. Nazeeruddin and M. Gratzel, Nature, 2013, 499, 316319.

6 N. J. Jeon, J. H. Noh, Y. C. Kim, W. S. Yang, S. Ryu and S. I. Seok, Nat. Mater., 2014, 13, 897-903.

7 N. J. Jeon, J. H. Noh, W. S. Yang, Y. C. Kim, S. Ryu, J. Seo and S. I. Seok, Nature, 2015, 517, 476-480. 
8 M. Saliba, T. Matsui, J.-Y. Seo, K. Domanski, J.-P. CorreaBaena, M. K. Nazeeruddin, S. M. Zakeeruddin, W. Tress, A. Abate, A. Hagfeldt and M. Gratzel, Energy Environ. Sci., 2016, 9, 1989-1997.

9 T. Leijtens, G. E. Eperon, S. Pathak, A. Abate, M. M. Lee and H. J. Snaith, Nat. Commun., 2013, 4, 2885.

10 M. Gratzel, Nat. Mater., 2014, 13, 838-842.

11 J. H. Kim, S. T. Williams, N. Cho, C.-C. Chueh and A. K. Y. Jen, Adv. Energy Mater., 2015, 5, 1401229.

12 I. C. Smith, E. T. Hoke, D. Solis-Ibarra, M. D. McGehee and H. I. Karunadasa, Angew. Chem., 2014, 126, 11414-11417.

13 S. N. Habisreutinger, T. Leijtens, G. E. Eperon, S. D. Stranks, R. J. Nicholas and H. J. Snaith, Nano Lett., 2014, 14, 55615568.

14 Q. Jiang, D. Rebollar, J. Gong, E. L. Piacentino, C. Zheng and T. Xu, Angew. Chem., Int. Ed., 2015, 54, 7617-7620.

15 Y. Chen, B. Li, W. Huang, D. Gao and Z. Liang, Chem. Commun., 2015, 51, 11997-11999.

16 Q. Tai, P. You, H. Sang, Z. Liu, C. Hu, H. L. W. Chan and F. Yan, Nat. Commun., 2016, 7, 11105.

17 N. C. D. Nath, I. S. Jung, P.-J. Park and J.-J. Lee, Electrochim. Acta, 2015, 161, 95-99.

18 H. Greijer Agrell, J. Lindgren and A. Hagfeldt, Sol. Energy, 2003, 75, 169-180.

19 Q. Tai, P. You, H. Sang, Z. Liu, C. Hu, H. L. W. Chan and F. Yan, Nat. Commun., 2016, 7, 11105.

20 A. Amat, E. Mosconi, E. Ronca, C. Quarti, P. Umari, M. K. Nazeeruddin, M. Grätzel and F. De Angelis, Nano Lett., 2014, 14, 3608-3616.

21 G. Giorgi, J.-I. Fujisawa, H. Segawa and K. Yamashita, J. Phys. Chem. C, 2015, 119, 4694-4701.

22 H.-S. Kim, I.-H. Jang, N. Ahn, M. Choi, A. Guerrero, J. Bisquert and N.-G. Park, J. Phys. Chem. Lett., 2015, 6, 4633-4639.

23 A. D. Jodlowski, C. Roldán-Carmona, G. Grancini, M. Salado, M. Ralaiarisoa, S. Ahmad, N. Koch, L. Camacho, G. de
Miguel and M. K. Nazeeruddin, Nat. Energy, 2017, 2, 972979.

24 L. Dimesso, A. Quintilla, Y. M. Kim, U. Lemmer and W. Jaegermann, Mater. Sci. Eng., B, 2016, 204, 27-33.

25 Y. Iwadate, K. Kawamura, K. Igarashi and J. Mochinaga, J. Phys. Chem., 1982, 86, 5205-5208.

26 G. Kieslich, S. Sun and A. K. Cheetham, Chem. Sci., 2015, 6, 3430-3433.

27 J. D. Patel, F. Mighri, A. Ajji and S. d. Elkoun, Mater. Sci. Appl., 2012, 03(02), 4.

28 S. S. Rao, I. K. Durga, C. V. Tulasi-Varma, D. Punnoose, L. J. Cheol and H.-J. Kim, New J. Chem., 2015, 39, 7379-7388.

29 N. Ahn, D.-Y. Son, I.-H. Jang, S. M. Kang, M. Choi and N.-G. Park, J. Am. Chem. Soc., 2015, 137, 8696-8699.

30 J.-W. Lee, H.-S. Kim and N.-G. Park, Acc. Chem. Res., 2016, 49, 311-319.

31 X. Lu, Z. Zhuang, Q. Peng and Y. Li, Chem. Commun., 2011, 47, 3141-3143.

32 N. J. Jeon, J. Lee, J. H. Noh, M. K. Nazeeruddin, M. Grätzel and S. I. Seok, J. Am. Chem. Soc., 2013, 135, 19087-19090.

33 S. Mastroianni, F. D. Heinz, J. H. Im, W. Veurman, M. Padilla, M. C. Schubert, U. Wurfel, M. Gratzel, N. G. Park and A. Hinsch, Nanoscale, 2015, 7, 19653-19662.

34 Y. Li, W. Yan, Y. Li, S. Wang, W. Wang, Z. Bian, L. Xiao and Q. Gong, Sci. Rep., 2015, 5, 14485.

35 L. Qie, W. Chen, X. Xiong, C. Hu, F. Zou, P. Hu and Y. Huang, Adv. Sci., 2015, 2, 1-6.

36 N. C. D. Nath, S. Sarker, A. J. Saleh Ahammad and J.-J. Lee, Phys. Chem. Chem. Phys., 2012, 14, 4333-4338.

37 G. I. Lee, N. C. D. Nath, S. Sarker, W. H. Shin, A. J. S. Ahammad, J. K. Kang and J.-J. Lee, Phys. Chem. Chem. Phys., 2012, 14, 5255-5259.

38 D. Cortecchia, H. A. Dewi, J. Yin, A. Bruno, S. Chen, T. Baikie, P. P. Boix, M. Grätzel, S. Mhaisalkar, C. Soci and N. Mathews, Inorg. Chem., 2016, 55, 1044-1052. 